\title{
Classification of Intracerebral Haemorrhages
}

\author{
Renan Domingues, ${ }^{1,4}$ Costanza Rossi ${ }^{2}$ and Charlotte Cordonnier ${ }^{3}$
}

1. Neurologist and Professor; 2. Neurologist; 3. Neurologist and Professor, Department of Neurology, University of Lille Nord de France, UDSL, CHU Lille, EA 1046, Lille, France; 4. Neurologist and Professor, CAPES Foundation, Ministry of Education, Brasilia-DF, Brazil

\begin{abstract}
Spontaneous intracerebral haemorrhage (ICH) is defined as a collection of blood in the cerebral parenchyma that is not caused by trauma. $\mathrm{ICH}$ is the second most frequent cause of stroke, accounting for $10-15 \%$ of all cases in high-income countries and about $20 \%$ in low- to middle-income countries. Despite an apparent stability of incidence over the past decades, the profile of ICH has changed: there are fewer deep ICHs associated with pre-stroke hypertension, whereas the increasing age of the population associated with a more extensive use of antithrombotic drugs leads to an increase of lobar ICH. Deep perforating vasculopathy remains the most important cause of ICH, followed by cerebral amyloid angiopathy, these two aetiologies account for nearly $70 \%$ of all ICH cases. Recent scientific evidence has highlighted new aspects of the pathophysiology of such disorders; nevertheless, the morbidity and mortality of ICH remain extremely high. In the present article, the different causes of $\mathrm{ICH}$ will be reviewed.
\end{abstract}

\section{Keywords}

Intracerebral haemorrhage (ICH), deep perforating vasculopathy, cerebral amyloid angiopathy (CAA), cerebral microbleeds (CMBS), brain intracranial vascular malformations, haemorrhagic transformation

\begin{abstract}
Disclosure: Renan Domingues has no conflicts of interest to declare. Costanza Rossi was an investigator in Brainsgate (Impact-24), Astra-Zeneca (SOCRATES), Pfizer (A9951024). No personal funding, all honoraria were paid to Adrinoid or Lille University Hospital. Charlotte Cordonnier was investigator in Photothera (NEST3), Brainsgate (Impact-24), Astra-Zeneca (SOCRATES). She is principal investigator in France for Pfizer (A9951024). She received speaker fees from Bayer, BMS. No personal funding, all honoraria were paid to Adrinoid or Lille University Hospital. No funding was received for the publication of this article.

Received: 17 May 2014 Accepted: 3 October 2014 Citation: European Neurological Review, 2014;9(2):129-35 DOI:10.17925/ENR.2014.09.02.129

Correspondence: Charlotte Cordonnier, Department of Neurology \& Stroke Unit, EA 1046, Lille University Hospital, 59037 cedex, Lille, France.

E: charlotte.cordonnier@chru-lille.fr
\end{abstract}

Spontaneous intracerebral haemorrhage $(\mathrm{ICH})$ is defined as a focal collection of blood within the brain parenchyma or ventricular system that is not caused by trauma. ${ }^{1}$ It is a heterogeneous condition resulting from several distinct underlying vasculopathies. Several interacting and overlapping risk factors may play a role in the vessel rupture.

The overall incidence of $\mathrm{ICH}$ ranges from 15 to 40 per 100,000 person-years. ${ }^{2-4}$ ICH accounts for 10-15\% of all strokes, but this proportion may be higher in Asian populations. ${ }^{5-7}$ The risk of $\mathrm{ICH}$ increases with age, being 9.6-fold higher in people over 85 years old compared with those less than 45 years of age. ${ }^{8}$ $\mathrm{ICH}$ incidence is higher in men, especially in Asian populations. ${ }^{3}$ Despite a significant improvement in ischaemic stroke management, $\mathrm{ICH}$ treatment has not significantly changed and this condition remains associated with a high case fatality rate in the first month, ranging from 13 to $61 \%$ of patients, with a median of $40 \%$ across studies. ${ }^{3}$

The clinical and epidemiological scenario of $\mathrm{ICH}$ has been changing in the last decades. ${ }^{29,10}$ Despite an overall stable incidence of $\mathrm{ICH}$, the incidence among people older than 75 years has increased and the incidence among people younger than 60 years has decreased, with a larger proportion of lobar haemorrhages, suggesting that vasculopathies more strongly associated with the elderly, particularly cerebral amyloid angiopathy (CAA), represent an increasing proportion within the aetiological distribution of $\mathrm{ICH} .{ }^{10}$ The poor prognosis of $\mathrm{ICH}$ may be partly due to our poor understanding of this heterogeneous disease. Herein, we review the different causes of $\mathrm{ICH}$.

\section{Anatomical Distribution (see Figure 1)}

ICH location can be classified as deep, lobar and infratentorial (involving the cerebellum and/or the brainstem). The anatomical distribution of the haemorrhage and its extension to other compartments (subarachnoid, subdural, intraventricular) may bring clues to identify the underlying cause of the bleeding.

Our knowledge on the anatomical distribution remains imprecise because most estimates are based on hospital series, which suffer from bias (referral is less often considered for moribund patients or, at the other extreme, for patients with only mild deficits), and populationbased studies, which are unbiased might contain a small proportion of haemorrhages precluding any further anatomical subdivision. ${ }^{19,11}$ In population-based registries, deep ICH accounts for 60-65\% while lobar $\mathrm{ICH}$ accounts for $31-40 \%$ of all ICH cases. 911 Multiple ICH accounts from $0.7-4.7 \%{ }^{12,13}$ of all ICH cases.

The pooled 1-year survival estimate in nine population-based studies was $46 \%$ (95\% confidence interval [CI] 43 to 49 ), while when location is considered the 1-year survival was $45-59 \%$ after lobar ICH, 45 to $59 \%$ after deep $\mathrm{ICH}$ and 40 to $54 \%$ after infratentorial $\mathrm{ICH} .{ }^{14}$

The most frequent cause of deep ICH is deep perforating vasculopathy that supervenes mostly in small perforating arterioles (50-700 $\mu \mathrm{m}$ in diameter) originating from the middle cerebral artery and from the basilar artery, thus explaining the classic location in the basal ganglia 


\section{Figure 1. Deep Perforating Vasculopathy Magnetic Resonance Imaging Findings}

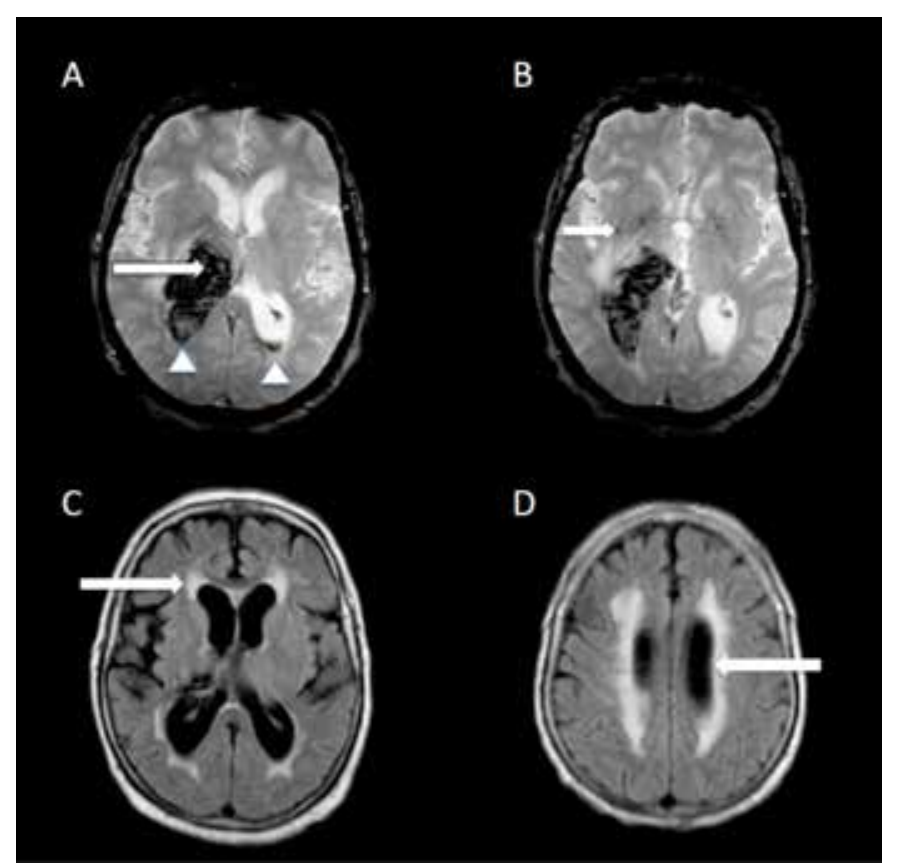

(A) Axial slice, T2* Gradient echo, showing right thalamic haemorrhage (white arrow) with intraventricular extension (heads of arrows). (B) Axial slice, T2* Gradient echo showing another characteristic feature of deep perforating vasculopathy: deep cerebral microbleeds located in right external capsule (white arrow). (C) and (D) Axial slices, fluid-attenuated inversion recovery (FLAIR) sequence, showing extensive white matter damage involving subcortical regions, resulting also from deep perforating vasculopathy (white arrows).

and brainstem. Deep ICH may be restricted to brain parenchyma or may extend to the ventricules. Intraventricular haemorrhage (IVH) is a frequent complication occurring in nearly $50 \%$ of $\mathrm{ICH}$ patients, and it is a predictor of poor outcome. ${ }^{15}$ The risk of bleeding in patients with deep perforating vasculopathy might be enhanced in patients receiving oral anticoagulants ${ }^{16}$ and among patients with heavy alcohol consumption history. ${ }^{17}$

Hypertension was found to be twice as common a risk factor for patients with deep $\mathrm{ICH}$ than with lobar $\mathrm{ICH}$, particularly in younger age groups (odds ratio [OR] 2.27, $95 \% \mathrm{Cl} 1.94$ to 2.66). These findings are, however, heavily influenced by studies with less robust methods. In the methodologically more rigorous studies, a smaller, but still statistically significant, excess of hypertension among patients with deep ICH was found (OR 1.50, $95 \% \mathrm{Cl} 1.09$ to 2.07). Further large, methodologically robust studies are needed to determine accurately the relative contribution of hypertension to deep and lobar $\mathrm{ICH}$ in different age groups. ${ }^{18}$ Although deep perforating vasculopathy is the most frequent cause, other disorders, such as intracranial vascular malformations (IVMs), may less frequently lead to deep $\mathrm{ICH} .{ }^{19}$

Lobar ICH can result from several distinct diseases. The most common is CAA. The pathological process seen in CAA occurs in small- to medium-sized leptomeningeal and cortical vessels (especially in the occipital and temporal regions), ${ }^{20}$ while vessels in deep areas (thalamus, basal ganglia as well as brainstem) are usually spared. A recent population-based study showed an important increase $(\sim 80 \%)$ in $\mathrm{ICH}$ incidence among people aged $\geq 75$ years. This result was attributed to a twofold increase in lobar $\mathrm{ICH}$, concomitantly with an observed rise in the premorbid use of antithrombotics at this age. These results suggest that some bleeding-prone vasculopathies in the elderly are more likely to bleed when antithrombotic drugs are used, as illustrated by the rise in the incidence of lobar $\mathrm{ICH}$, in which CAA may be strongly implicated..$^{10}$ Intracranial vascular malformations, brain tumours, cerebral venous thrombosis (CVT), haemorrhagic transformation $(\mathrm{HT})$, other vasculopathies and systemic diseases may also lead to lobar $\mathrm{ICH}$.

\section{Diagnostic Work-up}

The importance of the diagnostic work-up relies on the identification of the $\mathrm{ICH}$ but also of other neuroradiological biomarkers that can give clues to detect the underlying cause of the haemorrhage.

At admission, after the first brain image demonstrating the $\mathrm{ICH}$, it is not always clear whether, how and when to undertake further radiological investigation. In a survey of current practice in three European countries, younger patient age strongly influenced whether further investigation of $\mathrm{ICH}$ was performed, followed by the absence of prestroke hypertension and lobar ICH location. ${ }^{21}$ There is no general consensus concerning the choice and the timing of neuroradiological work-up for $\mathrm{ICH}_{.}{ }^{22}$ The American Heart Association/American Stroke Association ${ }^{23}$ recommended rapid brain computed tomography (CT) or magnetic resonance imaging (MRI) to distinguish $\mathrm{ICH}$ from ischaemic stroke and further vessel examination when structural underlying lesions are suspected. Besides vessel imaging, exploring brain parenchyma with MRI might bring additional clues to the underlying vessel disease. ${ }^{24}$

Brain CT detects symptomatic ICH within minutes of symptom onset but may lack sensitivity if delayed for $>1$ week after ICH onset. ${ }^{25}$ Hyperacute CT angiography followed by a post-contrast scan may identify a 'spot sign' - one or more hyperintense spots in the haemorrhage representing a contrast leak. ${ }^{26}$ Its presence might suggest a risk of haematoma expansion, poor outcome and mortality, even if the translation of its value into clinical practice remains controversial. ${ }^{27} \mathrm{CT}$ venography is useful to search for a venous thrombosis. ${ }^{28}$

Gradient recalled echo (GRE) T2* sequences identify the ICH soon after onset and reliably detect chronic post-haemorrhagic iron deposits. Conventional sequences may give indirect clues for a diagnosis: old lobar haemorrhages in a context of an acute lobar ICH suggesting CAA; white matter hyperintensities and lacunes of presumed vascular origin in a context of deep ICH suggesting deep perforating vasculopathy; acute lesions in diffusion-weighted imaging (DWI) in other arterial territories suggesting a HT of an infarct. MR-venography is useful to search for a CVT. Intracranial magnetic resonance angiography (MRA) associated with dynamic sequences (4D-MRA) has been evaluated in small studies on arteriovenous malformation (AVM), arteriovenous fistula (AVF) and it is emerging as an alternative to digital subtraction angiography (DSA) in the diagnosis and follow-up of these lesions, even though it may not fully substitute DSA due to limitations in spatial and temporal resolution. ${ }^{29,30}$ In patients with $\mathrm{ICH}$, conventional DSA remains the gold standard to detect underlying vascular lesions (AVM, AVF and arterial aneurysms). This should apply to all patients with $\mathrm{ICH}$, provided they are fit to undergo DSA, or if no other cause is identified.

Imaging data may also be used as part of prognostic scores predicting clinical outcome after acute $\mathrm{ICH}$. After the ascertainment of the haemorrhagic nature of the stroke, a swift diagnosis of the underlying cause can expedite management to improve outcome and/or prevent recurrent $\mathrm{ICH}$. 
Table 1: Most Frequent Causes of Non-traumatic Intracerebral Haemorrhage

\begin{tabular}{|c|c|c|}
\hline Aetiology & Main Features & Associated Radiological Findings \\
\hline Deep perforating vasculopathy & $\begin{array}{l}\text { - Hypertension is the most important risk factor } \\
\text { - Most frequently associated with deep ICH }\end{array}$ & $\begin{array}{l}\text { - Lacunes } \\
\text { - White matter hyperintensities } \\
\text { - Deep CMB } \\
\text { - Recent small subcortical infarcts } \\
\text { - Brain atrophy }\end{array}$ \\
\hline CAA & $\begin{array}{l}\text { - Age >55 years } \\
\text { - Lobar ICH without any other detected cause } \\
\text { - Classified according to the Boston criteria }\end{array}$ & $\begin{array}{l}\text { - Lobar CMB } \\
\text { - Superficial siderosis } \\
\text { - White matter hyperintensities } \\
\text { - Cortical microinfarcts } \\
\text { - Enlarged perivascular spaces }\end{array}$ \\
\hline Brain AVM & $\begin{array}{l}\text { - Clinical history of seizures and focal neurological deficits } \\
\text { may be present } \\
\text { - DSA remains the gold standard for the diagnosis and follow-up }\end{array}$ & $\begin{array}{l}\text { - } \mathrm{CT} \text { angiography and MRI with dynamic sequences (4D-MRI) are } \\
\text { sensitive diagnostic tools }\end{array}$ \\
\hline Cerebral CM & $\begin{array}{l}\text { - History of previous epilepsy may be present } \\
\text { - Diagnosis is made by MRI }\end{array}$ & $\begin{array}{l}\text { - Single or multiple cerebral CM } \\
\text { - Occasionally calcified }\end{array}$ \\
\hline Dural arteriovenous fistula & $\begin{array}{l}\text { - History of pulsatile tinnitus } \\
\text { - Often is an acquired lesion (thrombotic, traumatic or neoplastic } \\
\text { occlusion of a major sinus) }\end{array}$ & $\begin{array}{l}\text { - Meningeal artery supply draining into a sinus or meningeal vein } \\
\text { - ICH is usually superficial and can be associated to SAH/SDH }\end{array}$ \\
\hline Haemorrhagic transformation & $\begin{array}{l}\text { - Occurs in } 15 \% \text { of patients with cerebral infarction } \\
\text { - Risk factors of HT: early use/larger doses of anti-thrombotic } \\
\text { agents, cardioembolic stroke }\end{array}$ & $\begin{array}{l}\text { - Non-homogeneous haemorrhagic lesion } \\
\text { - Bleeding within a larger territorial infarct on MRI } \\
\text { - Location confined to a single arterial territory }\end{array}$ \\
\hline CVT & $\begin{array}{l}\text { - Usually associated with other conditions, such as prothrombotic } \\
\text { disorders, cancer, haematological diseases, vasculitis and } \\
\text { other inflammatory systemic disorders, pregnancy and puerperium, } \\
\text { infections, as well as several local causes, such as brain tumours, } \\
\text { AVM, head trauma, CNS infections and infections of the ear, sinus, } \\
\text { mouth, face or neck }\end{array}$ & $\begin{array}{l}\text { - Haemorrhage is usually preceded by other neurological } \\
\text { signs and symptoms } \\
\text { - Multiple haemorrhages } \\
\text { - CT or MR venography are efficient to show thrombosed } \\
\text { sinus/cortical vein butMR is preferred because of CT bone artefact }\end{array}$ \\
\hline RCVS & $\begin{array}{l}\text { - More frequent among women } \\
\text { - Thunderclap headache } \\
\text { - Differential diagnosis with subarachnoid haemorrhage }\end{array}$ & $\begin{array}{l}\text { - Angiography shows areas of arterial constriction and dilatation } \\
\text { (spontaneously reversible within } 3 \text { months) }\end{array}$ \\
\hline Primary or systemic vasculitis & $\begin{array}{l}\text { - Presence of laboratorial or radiological features suggestive } \\
\text { of vasculitis } \\
\text { - Increased CSF cell count } \\
\text { - Diagnosis confirmation requires neuropathological evidence } \\
\text { of cerebral vasculitis }\end{array}$ & $\begin{array}{l}\text { - Multifocal white matter lesions } \\
\text { - Angiographic multifocal segmental occlusion, collateral } \\
\text { vessel formation, and prolonged circulation }\end{array}$ \\
\hline Infective endocarditis & $\begin{array}{l}\text { - Fever and changes in white blood cell count } \\
\text { - Evidence of systemic embolism }\end{array}$ & $\begin{array}{l}\text { - Associated ischaemic lesions } \\
\text { - Multiple CMB } \\
\text { - Angiographic evidence of mycotic aneurysm }\end{array}$ \\
\hline $\begin{array}{l}\text { Brain tumours and brain } \\
\text { metastases }\end{array}$ & $\begin{array}{l}\text { - Previous history of tumour and/or radiological evidence of } \\
\text { other cerebral metastases }\end{array}$ & $\begin{array}{l}\text { - Definitive diagnosis requires histological confirmation of the } \\
\text { presence of a brain tumour with spatial relationship with the ICH } \\
\text { - Contrast CT or MRI suggesting a tumour }\end{array}$ \\
\hline
\end{tabular}

$A V M=$ arteriovenous malformation; $C A A=$ cerebral amyloid angiopathy; $C S F=$ cerebrospinal fluid; $C M=$ cavernous malformations; $C M B=$ cerebral microbleeds; $C N S=$ central nervous system; $C T=$ computed tomography; $C V T=$ cerebral venous thrombosis; DSA = digital subtraction angiography; ICH = intracerebral haemorrhage; $M R I=$ magnetic resonance imaging; $R C V S=$ reversible cerebral vasoconstriction syndrome; SAH = subarachnoid haemorrhage; $S D H=$ subdural haematoma.

\section{Causes of Intracerebral Haemorrhage (see Table 1)}

There have been some attempts to propose an aetiological classification of $\mathrm{ICH}_{1}{ }^{31}$ but no consensus has yet been achieved. Of note, the recent Structural lesion, Medication, Amyloid angiopathy, Systemic/other disease, Hypertension, Undetermined (SMASH-U) classification ${ }^{31}$ describes categories that are mutually exclusive. In clinical practice, a single $\mathrm{ICH}$ may result from several factors. Clinicians should therefore distinguish: (i) predisposing risk factors, such as older age, hypertension, ${ }^{32}$ high alcohol intake; ${ }^{-17}$ and (ii) precipitating factors, such as use of oral anticoagulants. ${ }^{16}$ For example, in an elderly patient with past history of hypertension and myocardial infarction treated with clopidogrel, both hypertension and antithrombotic may contribute to the deep $\mathrm{ICH}$ eventually due to deep perforating vasculopathy. Therefore, it may be difficult to establish in a specific patient to which extent these elements interacted. Histological proof should remain the gold standard.

\section{Deep Perforating Vasculopathy (see Figure 2)}

Deep perforating vasculopathy accounts for nearly $50 \%$ of the $\mathrm{ICH}$ worldwide. ${ }^{5,833}$ Chronic arterial hypertension is the most frequent risk factor associated with deep perforating vasculopathy. ${ }^{32}$ The current understanding of the arterial pathology underlying deep haemorrhage is largely based on studies conducted in the 1960s and 1970s. ${ }^{34}$ The proposed pathophysiological basis includes a reactive hyperplasia of vessel wall components followed by microscopic degenerative changes with collagen deposition, leading to reduced vascular reactivity and enhanced vessel wall fragility of smallto-medium penetrating vessels. ${ }^{35}$ Deep perforating vasculopathy usually occurs in lenticulostriate arteries originating from middle cerebral artery and perforating arteries that arise from the basilar artery, this explains the classic location of deep ICH in the basal ganglia and brainstem. ${ }^{35}$ The hypertensive changes (also known as arteriosclerosis) affecting perforating vessels may lead to lacunar 


\section{Figure 2: Cerebral Microbleeds}

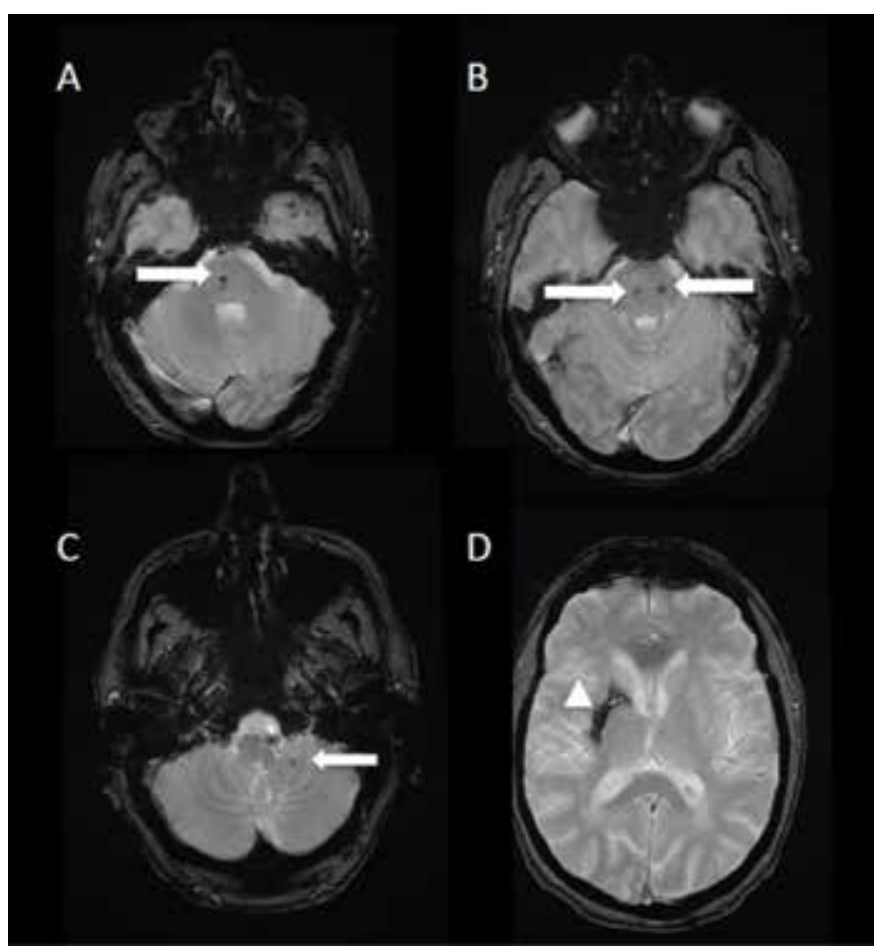

(A) and (B) Axial slices, T2* Gradient echo, showing right and left brainstem cerebral microbleeds (CMBS) (white arrows). (C) Axial slice, T2* Gradient echo showing one CMB in the left cerebellar hemisphere (white arrow). (D) Axial slice, T2* Gradient echo, of the same patient showing a chronic intracerebral haemorrhage in the right lenticular nucleus (head of arrow).

\section{Figure 3: Cerebral Amyloid Angiopathy Magnetic Resonance Imaging Findings}

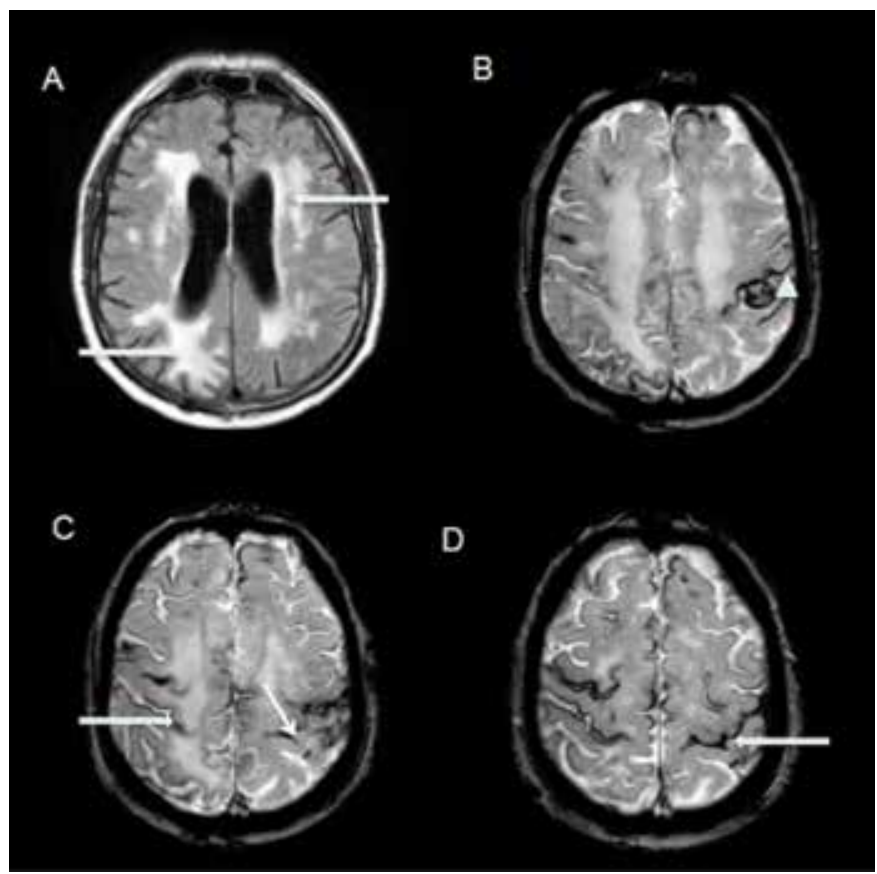

(A) Axial slice, fluid-attenuated inversion recovery (FLAIR) sequence, showing extensive white matter hyperintensities in periventricular and subcortical regions (white arrows). (B) Axial slice, T2* Gradient echo showing a left lobar (parietal) intracerebral haemorrhage (head of arrow). (C) and (D) Axial slice, T2* Gradient echo showing diffuse cortical superficial siderosis (white arrows) and one left parietal lobar cerebral microbleed (head of arrow).

infarction in some circumstances and to deep ICH in others. Given the absence of anatomical demonstration of perforating arteries in the cerebellum, the implication of deep perforating vasculopathy in the cerebellar $\mathrm{ICH}$ remains controversial.

In the absence of prospectively validated diagnostic criteria, clinicians should keep in mind that the presence of risk factors is neither necessary nor sufficient to conclude that a deep ICH is due to arteriolosclerosis. Indeed, the prevalence of hypertension is also very high in patients with lobar $\mathrm{ICH}^{10}$ Because this vasculopathy has two modalities of expression (haemorrhagic and occlusive), clinicians should search for other radiological markers of the disease, such as the presence of recent small subcortical infarcts, white matter hyperintensities, lacunes of presumed vascular origin, brain atrophy, cerebral microbleeds (CMB) in the basal ganglia and pons. ${ }^{18,36}$

\section{Cerebral Amyloid Angiopathy}

CAA-related $\mathrm{ICH}$ preferentially affects cortical-subcortical (lobar) regions, less commonly the cerebellum and, rarely, deep or brainstem structures, reflecting the distribution of the underlying microangiopathy. ${ }^{37}$ The predilection for the occipital lobes ${ }^{20}$ is not well understood but one hypothesis is that greater tortuosity of occipital small arteries impairs perivascular drainage. ${ }^{38}$ Clinicopathological studies suggest that CAA-related $\mathrm{ICH}$ account for at least 5-20 \% of all spontaneous $\mathrm{ICH}^{39}$ However, there are methodological challenges in attributing $\mathrm{ICH}$ to CAA as most pathological case control studies did not systematically control for potential confounding risk factors for CAA, including cognitive impairment, ethnicity or age. ${ }^{37}$ Advancing age is the strongest known risk factor for developing CAA. ${ }^{40}$ Apolipoprotein $\mathrm{E} \varepsilon 4$ and $\varepsilon 2$ polymorphisms are both related with increased risk of CAA-related $\mathrm{ICH} .{ }^{37}$

Besides ICH, CAA is also associated with ischaemic damage, such as cortical-subcortical microinfarcts, and white matter hyperintensities. These ischaemic lesions probably result from reduced perfusion by CAA-affected arteries. ${ }^{39}$

Neuroradiological manifestations of CAA are: strictly corticosubcortical CMB, convexity subarachnoid haemorrhages (SAHS)/ superficial siderosis (SS), white matter hyperintensities and silent small cortical acute ischaemic lesions (see Figure 3). White-matter dilated perivascular spaces could also be an interesting biomarker of CAA. Lobar CMB have been considered as a marker of CAA, as the histological characteristics of the vessels involved in lobar CMB are similar to those of CAA, suggesting that lobar CMB and CAA may be different expressions of the same pathological process. ${ }^{41}$ Recent data have implicated acute or chronic haemorrhage within or adjacent to the cortical sulci (often described as SS when chronic or as convexity SAH when acute) as another form of bleeding associated with CAA. SS seems also to have clinical meaning in CAA as a trigger of transient focal neurological symptoms ${ }^{42}$ and a possible marker of increased risk for future $\mathrm{ICH}$. White matter hyperintensities of presumed vascular origin, visualised on T2-weighted or fluid-attenuated inversion recovery (FLAIR) MRI sequences, are a ubiquitous phenomenon of ageing, but occur with much greater volume in individuals diagnosed with CAA than in those with healthy ageing Alzheimer's disease or mild cognitive impairment. Microinfarcts can be detected as clinically silent foci of restricted diffusion on DWI sequences. ${ }^{43}$ Such lesions have been reported in about $10-20 \%$ of patients with CAA imaged either at the time of $\mathrm{ICH}$ or during follow-up, suggesting that they might represent a marker of ongoing brain injury related to CAA. Enlarged or dilated perivascular spaces, presumed to be due to the accumulation of interstitial fluid, have been linked to the presence and severity of cerebral small-vessel disease. CAA seems to be 
Table 2: Boston Criteria for Diagnosis of Cerebral Amyloid Angiopathy in Patients Suffering a Lobar Intracerebral Haemorrhage

$\begin{array}{llll} & \text { Classic Boston criteria } & \text { Modified Boston criteria } & \text { Comments } \\ \text { Definite CAA } & \text { Full post-mortem examination demonstrating: } & \text { No modification }{ }^{\text {a }} & \text { The term 'haemorrhage' referred, in the pathological } \\ & \text { - Lobar, cortical or cortico-subcortical haemorrhage } & \text { validation, to lobar ICH. However, some authors suggest } \\ & \text { - Severe CAA with vasculopathy } & \text { that multiple CMB in cortical or cortico-subcortical regions, } \\ & \text { - Absence of other diagnostic lesion* } & \text { without lobar ICH, may be considered as probable CAA. }\end{array}$

Probable CAA Clinical data and pathological tissue (evacuated No modificationa with supporting haematoma or cortical biopsy) demonstrating:

pathology - Lobar, cortical or cortico-subcortical haemorrhage

- Some degree of CAA in specimen

- Absence of other diagnostic lesion*

Probable CAA Clinical data and MRI or CT demonstrating: Clinical data and MRI or CT

- Multiple haemorrhages restricted to lobar, demonstrating:

cortical or cortico-subcortical regions (cerebellar • Multiple haemorrhages restricted

haemorrhage allowed) to lobar, cortical or cortico-subcortical

- Age $\geq 55$ years regions (cerebellar haemorrhage allowed) or

- Absence of other cause of haemorrhage* - Single lobar, cortical or

cortico-subcortical haemorrhage and

focal $^{\mathrm{b}}$ or disseminated ${ }^{\mathrm{c}}$ superficial siderosis

- Age $\geq 55$ years

- Absence of other cause of haemorrhage

or superficial siderosis*

Possible CAA Clinical data and MRI or CT demonstrating:

Clinical data and MRI or CT demonstrating

- Single lobar, cortical or cortico-subcortical

- Single lobar, cortical or cortico-subcortical

haemorrhage

- Age $\geq 55$ years

haemorrhage or focal ${ }^{\mathrm{b}}$ or disseminated ${ }^{c}$

superficial siderosis

- Absence of other cause of haemorrhage* $\quad$ Age $\geq 55$ years

- Absence of other cause of haemorrhage or

superficial siderosis*

Adapted from Knudsen et al. 2001 and Linn et al. 2010.43,45 For absence of other causes/other diagnostic lesion, a complete diagnostic workup aimed at excluding in the acute phase all the causes of symptomatic lobar haemorrhage (cf Table 1), magnetic resonance imaging (MRI) at 6 months follow-up and in selected cases digital subtraction angiography (DSA) in the acute phase/follow-up are necessary. ${ }^{45}{ }^{*}$ Other causes of intracerebral haemorrhage (ICH) that question the diagnosis of cerebral amyloid angiopathy (CAA) are: excessive warfarin dose (international normalised ratio [INR] >3.0) (INR 3.0 or other non-specific laboratory abnormalities are permitted for diagnosis of possible CAA); antecedent of head trauma or ischaemic stroke; haemorrhagic transformation of an ischaemic stroke; arteriovenous malformation; central nervous system (CNS tumour), vascular malformation or vasculitis; and blood dyscrasia or coagulopathy. The value of 3 remains controversial. ${ }^{a}$ No modification compared with the classic Boston criteria; ${ }^{b}$ Siderosis restricted to three or fewer sulci; 'siderosis affecting at least four sulci. CT = computed tomography.

preferentially associated with high numbers of visible perivascular spaces in the centrum semiovale. ${ }^{44}$

The Boston criteria ${ }^{45}$ (see Table 2) represented an effort to estimate the likelihood of the presence of CAA in patients with $\mathrm{ICH}$ with categories of probable and possible CAA based on the pattern and number of haemorrhagic lesions on neuroimaging. ${ }^{45}$ These criteria are widely used but a few limitations have to be highlighted. ${ }^{46}$ In the original version, the authors took into account only patients with symptomatic lobar $\mathrm{ICH}$, not considering other CAA clinical manifestations, such as cognitive decline or focal transient neurological symptoms. Furthermore, they did not validate the impact of other MRI biomarkers of CAA, such as the presence of strictly cortico-subcortical CMB or SS. Recent scientific evidence suggests that taking into account strictly lobar CMB and/ or SS together with the presence of symptomatic lobar $\mathrm{ICH}$ would allow to increase specificity and sensitivity of the Boston Criteria, thus identifying a higher number of patients suffering from CAA.47,48 The sensitivity and specificity of SS and lobar CMB for CAA have to be validated in larger prospective cohorts.

\section{Intracranial Vascular Malformations}

Several types of IVMs may cause ICH. Overall, patients with $\mathrm{ICH}$ due to vascular malformations have a better prognosis than patients with spontaneous ICH. ${ }^{49}$ In the Scottish population-based registry SIVMS, the crude detection rate (per 100,000 adults per year) was 2.27 for all IVMS, 1.12 for brain AVMs, 0.56 for cavernous malformations, 0.43 for venous malformations and 0.16 for dural AVMs. ${ }^{50}$

\section{Arteriovenous Malformations}

AVMs consist of a pial artery supply collected into a nidus and then on a draining vein. Half of the AVMs are revealed by an $\mathrm{ICH}^{51}$ Unruptured AVMs are associated with an annual haemorrhage rate of 2.3-2.8\%.51,52 Initial haemorrhagic AVM presentation, female sex and increasing age are major risk of recurrent $\mathrm{ICH}$. Some anatomical features, such as deep brain location or exclusive deep venous drainage, might also be considered as markers of haemorrhagic risk. ${ }^{51}$

\section{Cerebral Cavernous Malformations}

CCM are angiographically occult vascular malformations, consisting of blood vessels devoided of muscular and elastic tissue that are lined with endothelial cells without intervening brain tissue. They can be single or multiple and occasionally calcified. ${ }^{.5}$ The risk of $\mathrm{ICH}$ is around $6 \%$ per person-year. ${ }^{54} \mathrm{ICH}$ due to $\mathrm{CCM}$ occurs at a younger age and tends to be less disabling at onset than those due to other cerebral AVMs. Furthermore, CCM tend to cause small ICHs thus explaining a mild severity. CCM-related ICHs rarely have an extension to other compartments (subarachnoid, subdural or intraventricular) unlike half of the ICHs due to AVM and AVF.5. 
Figure 4: Haemorrhagic Infarct

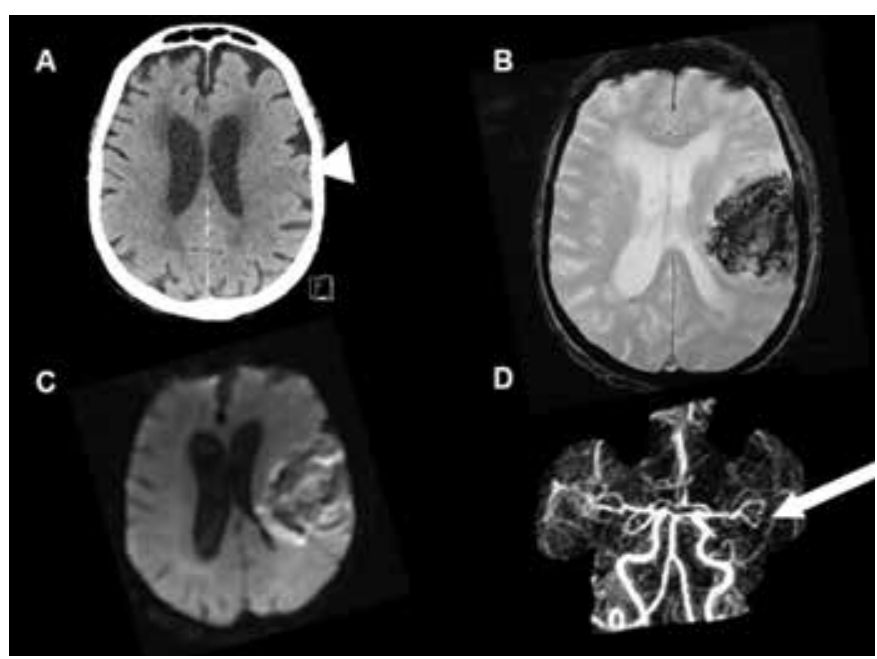

(A) Axial slice, non-contrast computed tomography (CT)-scan at admission showing early signs of a left acute ischaemic stroke (head of arrow). (B) Axial slice, T2* Gradient echo showing a large left lobar intracerebral haemorrhage (ICH). Without knowledge of the first CT-scan, this magnetic resonance image (MRI) would have been interpreted as a 'spontaneous' ICH. (C) Axial slice, diffusion-weighted imaging (DWI) sequence. The bleeding is so extensive that no underlying ischaemic process can be seen. (D). Time of flight sequences of the intracranial arteries. Left distal middle cerebral artery is occluded (white arrow)

\section{Haemorrhagic Transformation}

HT occurs in some patients with cerebral infarction (up to $15 \%$ in the acute phase of stroke, depending on patient selection and radiological criteria). ${ }^{56} \mathrm{HT}$ may be distinguished from a spontaneous $\mathrm{ICH}$ by the lack of homogeneity of the haemorrhagic lesion that lies within an area of infarction (appearing as an area of low density on CT or of hyperintensity in DWI sequences on MRI) with a typical location confined to a single arterial territory. Sometimes the haemorrhage is so dense that it would have been regarded as a so-called 'primary' $\mathrm{ICH}$, had not an earlier CT scan or MRI in the acute phase shown an infarct (see Figure $4 A$ ). The diagnostic challenge comes from the fact that in some patients the first radiological exam already shows blood and the underlying ischaemic process might be difficult to disentangle (see Figure $4 B$ ). An important diagnostic tool in this case is the DWI sequence that enables concomitant ischaemic lesions in the same or in other arterial territories to be disclosed. It is also important to explore intracranial vessels to search for an arterial occlusion (see Figure 4D).

\section{Systemic Disease and Brain Tumours/Metastases}

$\mathrm{ICH}$ can result from systemic conditions, such as liver diseases with abnormal coagulation, haematological malignancies and other haematological conditions with reduced platelet count, systemic infections, infective endocarditis and systemic vasculitis. ${ }^{57,58}$ Brain tumours may potentially bleed and represent $4.4 \%$ of all $\mathrm{ICH}^{59}$ Glioblastoma multiforme, oligodendroglioma and brain metastases from melanoma, renal cell carcinoma, thyroid carcinoma and choriocarcinoma (tumours associated with the higher risk of tumour associated-ICH). Intra-tumour neovascularisation, fragile vessels within tumour tissue and immature cell-to-cell junctions in tumour vasculature are reported as the mechanisms of tumour-associated $\mathrm{ICH}^{.59}$

\section{Cerebral Venous Thrombosis}

CVT is a rare type of cerebrovascular disease that accounts for $0.5 \%$ of all cases of stroke. CVT presents with a wide spectrum of signs and modes of onset, thus mimicking numerous other disorders. The most common symptoms and signs are unusual headache (which occurs in nearly $80 \%$ of the patients), seizures, focal neurological deficits, altered consciousness and papillary oedema, which can present in isolation or in association with other symptoms. ${ }^{28}$ In about $39 \%$ of cases, the $\mathrm{CVT}$ is associated with an $\mathrm{ICH} .{ }^{60} \mathrm{Haemorrhages}$ result from venous infarcts.

Several disorders can cause or predispose patients to CVT. These disorders include all medical and surgical causes of deep vein thrombosis, genetic and acquired prothrombotic disorders, cancer, haematological diseases, vasculitis and other inflammatory systemic disorders, pregnancy and puerperium, infections, as well as several local causes - such as brain tumours, AVMs, head trauma, central nervous system (CNS) infections and infections of the ear, sinus, mouth, face or neck. Diagnostic and therapeutic procedures such as lumbar puncture, jugular catheter and some drugs - in particular oral contraceptives, hormonal replacement therapy, steroids and oncology treatments - can also cause or predispose people to CVT. CVT is typically multifactorial, which means that the identification of a risk factor or even of a cause should not deter clinicians from looking for other risk factors, particularly congenital thrombophilia. ${ }^{61}$ The diagnosis can be suspected when the location of the $\mathrm{ICH}$ is: parasagittal (mono or bilateral) with thrombosis of the superior sagittal sinus, on the cerebral convexity (when the thrombosis involves a cortical vein) or in the temporal lobes with thrombosis of the lateral sinus. Extensive haemorrhages occur in only a minority of patients. CVT should be suspected especially when: (i) the bleeding is in a lobar location, (ii) the haemorrhage has been preceded by other signs and symptoms and (iii) the haemorrhage is multiple (mainly in the parasagittal or temporal regions). ${ }^{60,61}$

In case of CVT, even in the presence of massive $\mathrm{ICH}$, there is the indication of full-dose anticoagulation as first-line therapy..$^{60}$

\section{Reversible Cerebral Vasoconstriction Syndrome}

Reversible cerebral vasoconstriction syndrome (RCVS) is a rare condition that is characterised by the association of severe headaches (with or without additional neurological symptoms) and constriction of cerebral arteries that resolves spontaneously in 1 to 3 months. ${ }^{62}$ This disturbance may be spontaneous, while $25-60 \%$ of cases are secondary, mostly to exposure to vasoactive sympathomimetic or serotoninergic substances, and/or to the postpartum state..$^{63}$ The most common clinical feature is a severe acute headache ('thunderclap' headache) and the major complications are focal cortical SAHS (20$25 \%$ ) and ischaemic or haemorrhagic strokes (5-10\%). ${ }^{63}$ Parenchymal haemorrhages, which occurred in nearly $12 \%$ of all RCVS patients, ${ }^{62}$ are of variable volume, more frequently single than multiple, and lobar than deep and more often associated with another type of stroke (convexity haemorrhage or infarction, or both) than isolated. They occur early in the course of RCVS and are revealed mostly by a persisting focal deficit concomitant with thunderclap headache. However, causal relationship remains controversial.

\section{Conclusion}

In 2014, ICH remains a devastating disorder. There is no such thing as a 'primary' ICH like there is no primary ischaemic stroke. Disentangling the underlying vessel disease that eventually led to the bleeding might help tailoring new treatment strategies and preventing recurrent events. 
1. Sacco RL, Kasner SE, Broderick JP, et al., An updated definition of stroke for the 21st century: a statement for healthcare professionals from the American Heart Association/American Stroke Association, Stroke, 2013;44:2064-89.

2. Howard G, Cushman M, Howard VJ, et al., Risk factors for intracerebral hemorrhage: the REasons for geographic and racial differences in stroke (REGARDS) study, Stroke, 2013;44:1282-7.

3. van Asch CJ, Luitse MJ, Rinkel GJ, et al., Incidence, case fatality, and functional outcome of intracerebral haemorrhage over time, according to age, sex, and ethnic origin: a
systematic review and meta-analysis, Lancet Neurol, 2010;9:167-76.

4. Gaist D, Wallander MA, Gonzalez-Perez A, Garcia-Rodriguez $L A$, Incidence of hemorrhagic stroke in the genera population: validation of data from The Health Improvemen Network, Pharmacoepidemiol Drug Saf, 2013;22:176-82.

5. Provencio JJ, Da Silva IR, Manno EM, Intracerebra hemorrhage: new challenges and steps fo

6. Hong KS, Bang OY, Kang DW, et al., Stroke Statistics in Korea Part I. Epidemiology and Risk Factors: A Report from the Korean Stroke Society and Clinical Research Center for Stroke, I Stroke, 2013;15:2-20.

7. Tsai CF, Thomas B, Sudlow CL, Epidemiology of stroke and its subtypes in Chinese vs white populations: a systematic review, Neurology, 2013;81:264-72.

8. Algra A, Klijn CJ, Intracerebral haemorrhage: understanding racial differences in intracerebral haemorrhage, Nature Rev Neurol, 2013;9:364-5.

9. Lovelock CE, Molyneux AJ, Rothwell PM, Change in incidence and aetiology of intracerebral haemorrhage in Oxfordshire, UK, between 1981 and 2006: a population-based study, Lancet Neurol, 2007; 6:487-93.

10. Bejot Y, Cordonnier C, Durier J, et al., Intracerebral haemorrhage profiles are changing: results from the Dijon population-based study, Brain, 2013;136(Pt 2):658-64.

11. Labovitz DL, Halim A, Boden-Albala B, et al., The incidence of deep and lobar intracerebral hemorrhage in whites, blacks, and Hispanics, Neurology, 2005;65:518-22.

12. Yen $C P$, Lin $C L$, Kwan AL, et al., Simultaneous multiple hypertensive intracerebral haemorrhages, Acta Neurochir (Wien), 2005;147:393-9.

13. Sorimachi T, Ito $Y$ Morita $K$, Fujii $Y$, Microbleeds on gradientecho T2(*)-weighted MR images from patients with multiple simultaneous intracerebral haemorrhages, Acta Neurochir (Wien), 2007;149:171-6.

14. Poon MT, Fonville AF, Al-Shahi Salman R, Long-term prognosis after intracerebral haemorrhage: systematic review and meta-analysis, J Neurol Neurosurg Psychiatry, 2014;85:660-7.

15. Tuhrim S, Horowitz DR, Sacher M, Godbold JH, Volume of ventricular blood is an important determinant of outcome in supratentorial intracerebral hemorrhage, Crit Care Med, 1999;27:617-21.

16. Dequatre-Ponchelle $\mathrm{N}$, Henon $\mathrm{H}$, Pasquini M, et al., Vitamin $\mathrm{K}$ antagonists-associated cerebral hemorrhages: what are their characteristics? Stroke, 2013:44:350-5.

17. Casolla B, Dequatre-Ponchelle N, Rossi C, et al., Heavy alcoho intake and intracerebral hemorrhage: characteristics and effect on outcome, Neurology، 2012:79:1109-15.

18. Jackson $C A$, Sudlow $C L$, Is hypertension a more frequent risk factor for deep than for lobar supratentorial intracerebral haemorrhage?, J Neurol Neurosurg Psychiatry, 2006;77:1244-52.

9. Zheng $\mathrm{T}$, Wang $\mathrm{S}$, Barras $\mathrm{C}$, et al., Vascular imaging adds value in investigation of basal ganglia hemorrhage, I Clin Neurosci, 2012;19:277-80

20. Rosand J, Muzikansky A, Kumar A, et al., Spatial clustering of hemorrhages in probable cerebral amyloid angiopathy, Ann Neurol, 2005;58:459-62.

21. Cordonnier C, Klijn CJ, van Beijnum J, Al-Shahi Salman R, Radiological investigation of spontaneous intracerebral hemorrhage: systematic review and trinational survey, Stroke,
2010;41:685-90.

22. Al-Shahi Salman R, Labovitz DL, Stapf C, Spontaneous intracerebral haemorrhage, BMJ, 2009;339:b2586

23. Morgenstern LB, Hemphill JC 3rd, Anderson C, et al.; American Heart Association Stroke Council and Council on Cardiovascular Nursing. Guidelines for the management of spontaneous intracerebral hemorrhage: a guideline for healthcare professionals from the American Heart Association/American Stroke Association, Stroke, 2010;41:2108-29.

24. Wijman CA, Venkatasubramanian C, Bruins S, et al., Utility of early MRI in the diagnosis and management of acute spontaneous intracerebral hemorrhage, Cerebrovasc Dis, 2010;30:456-63.

25. Warlow C, Sudlow C, Dennis M, et al., Stroke, Lancet, 2003;362(9391):1211-24

26. Boulouis $\mathrm{G}$, Dumas A, Betensky RA, et al., Anatomic pattern of intracerebral hemorrhage expansion: relation to CT angiography spot sign and hematoma center, Stroke, 2014;45:1154-6.

27. Romero JM, Stroke: is spot sign the answer for intracerebral haemorrhage?, Nature Rev Neurol, 2012;8:300-1.

28. Bousser MG, Ferro JM, Cerebral venous thrombosis: an update, Lancet Neurol, 2007;6:162-70.

29. Evans AL, Coley SC, Wilkinson ID, Griffiths PD, First-line investigation of acute intracerebral hemorrhage using dynamic magnetic resonance angiography, Acta Radiol, 2005;46:625-30.

30. Hadizadeh DR, Kukuk GM, Steck DT, et al., Noninvasive evaluation of cerebral arteriovenous malformations by 4D-MRA for preoperative planning and postoperative followup in 56 patients: comparison with DSA and intraoperative findings, AJNR Am I Neuroradiol, 2012;33:1095-101.

31. Meretoja A, Strbian D, Putaala J, et al., SMASH-U: a proposal for etiologic classification of intracerebral hemorrhage, Stroke, 2012;43:2592-7.

32. Ariesen MJ, Claus SP, Rinkel GJ, Algra A, Risk factors for intracerebral hemorrhage in the general population: a systematic review, Stroke, 2003;34:2060-5.

33. IKram MA, Wieberdink RG, Koudstaal PJ, International epidemiology of intracerebral hemorrhage, Curr Atheroscl Rep, 2012:14:300-6.

34. Fisher $\mathrm{CM}$, Pathological observations in hypertensive cerebral hemorrhage, J Neuropathol Exp Neurol, 1971;30:536-50.

35. Wang QT, Tuhrim S, Etiologies of intracerebral hematomas, Curr Atheroscl Rep, 2012;14:314-21.

36. Wardlaw JM, Smith EE, Biessels GJ, et al., Neuroimaging standards for research into small vessel disease and its contribution to ageing and neurodegeneration, Lancet Neurol, 2013;12:822-38.

37. Charidimou A, Gang Q, Werring DJ, Sporadic cerebral amyloid angiopathy revisited: recent insights into pathophysiology and clinical spectrum, I Neurol Neurosurg Psychiatry. 2012;83:124-37.

38. Attems J, Jellinger $K$, Thal $D R$, Van Nostrand W, Review: sporadic cerebral amyloid angiopathy, Neuropathol App/ Neurobiol, 2011:37:75-93.

39. Maia LF, Mackenzie IR, Feldman HH, Clinical phenotypes of Cerebral Amyloid Angiopathy, J Neurol Sci, 2007;257 (1-2):23-30.

40. Viswanathan $A$, Greenberg SM, Cerebral amyloid angiopathy in the elderly, Ann Neurol, 2011;70:871-80.

41. Fisher M, French S, Ji P, Kim RC, Cerebral microbleeds in the elderly: a pathological analysis, Stroke, 2010;41:2782-5

2. Charidimou A, Jager RH, Fox Z, et al., Prevalence and mechanisms of cortical superficial siderosis in cerebra amyloid angiopathy, Neurology, 2013;81:626-32.

43. Gurol ME, Viswanathan A, Gidicsin C, et al., Cerebral amyloid angiopathy burden associated with leukoaraiosis: a positron emission tomography/magnetic resonance imaging study, Ann Neurol, 2013:73:529-36.

44. Charidimou A, Meegahage R, Fox Z, et al., Enlarged perivascular spaces as a marker of underlying arteriopathy in intracerebral haemorrhage: a multicentre MRI cohort study J Neurol Neurosurg Psychiatry, 2013;84:624-9.

45. Knudsen KA, Rosand J, Karluk D, Greenberg SM, Clinical diagnosis of cerebral amyloid angiopathy: validation of the Boston criteria, Neurology, 2001; 56:537-9.

46. Samarasekera N, Smith C, Al-Shahi Salman R, The association between cerebral amyloid angiopathy and intracerebral haemorrhage: systematic review and meta-analysis, J Neurol Neurosurg Psychiatry, 2012;83:275-81.

47. Linn J, Halpin A, Demaerel P, et al., Prevalence of superficial siderosis in patients with cerebral amyloid angiopathy, Neurology 2010:74:1346-50.

48. van Rooden S, van der Grond J, van den Boom R, et al, Descriptive analysis of the Boston criteria applied to a Dutch-type cerebral amyloid angiopathy population, Stroke, 2009;40:3022-7.

49. van Beijnum J, Lovelock $\mathrm{CE}$, Cordonnier C, et al., Outcome after spontaneous and arteriovenous malformation-related intracerebral haemorrhage: population-based studies, Brain, 2009;132(Pt 2):537-43.

50. Al-Shahi R, Bhattacharya JJ, Currie DG, et al., Scottish Intracranial Vascular Malformation Study (SIVMS): evaluation of methods, ICD-10 coding, and potential sources of bias in a prospective, population-based cohort, Stroke, 2003;34:1156-62.

51. Kim H, Al-Shahi Salman R, McCulloch CE, et al.; MARS Coinvestigators. Untreated brain arteriovenous malformation: Patient-level meta-analysis of hemorrhage predictors, Neurology, 2014;83:590-7.

52. Mohr JP, Parides MK, Stapf C, et al., Medical management with or without interventional therapy for unruptured brain arteriovenous malformations (ARUBA): a multicentre, nonblinded, randomised trial, Lancet, 2014;383(9917):614-21.

53. Al-Shahi Salman R, Berg MJ, Morrison L, Awad IA, Hemorrhage from cavernous malformations of the brain: definition and reporting standards. Angioma Alliance Scientific Advisory Board, Stroke, 2008;39:3222-30.

54. Al-Shahi Salman R, Hall JM, Horne MA, et al., Untreated clinical course of cerebral cavernous malformations: a prospective, population-based cohort study, Lancet Neurol, 2012:11:217-24.

55. Cordonnier C, Al-Shahi Salman R, Bhattacharya JJ, et al., Differences between intracranial vascular malformation types in the characteristics of their presenting haemorrhages: prospective, population-based study, I Neurol Neurosurg Psychiatry, 2008;79:47-51.

56. Paciaroni M, Agnelli G, Corea F, et al., Early hemorrhagic transformation of brain infarction: rate, predictive factors, and influence on clinical outcome: results of a prospective multicenter study, Stroke, 2008;39:2249-56.

57. Alberto San Roman J, Vilacosta I, Neurological complications in infective endocarditis, European Heart Journal, 2013;34:3467-8a

58. Mencacci NE, Bersano A, Cinnante CM, et al., Intracerebral haemorrhage, a possible presentation in Churg-Strauss syndrome: case report and review of the literature, $J$ Neurol syndrome: case report a

59. Licata B, Turazzi S, Bleeding cerebral neoplasms with symptomatic hematoma, J Neurosurg Sci, 2003;47(4):201-10.

60. Ferro JM, Canhao P, Stam J, et al., Prognosis of cerebral vein and dural sinus thrombosis: results of the International Study on Cerebral Vein and Dural Sinus Thrombosis (ISCVT), Stroke, 2004;35:664-70

61. Stam J, Thrombosis of the cerebral veins and sinuses, N Eng/ J Med, 2005;352:1791-8.

62. Ducros A, Reversible cerebral vasoconstriction syndrome, Lancet Neurol, 2012;11:906-17.

63. Ducros A, Boukobza M, Porcher R, et al., The clinical and radiological spectrum of reversible cerebral vasoconstriction syndrome. A prospective series of 67 patients, Brain, 2007:130(Pt 12):3091-101. 